Portland State University

PDXScholar

5-10-1995

\title{
Empowering ESL Students for Out of Classroom Learning
}

Jay Stanley Neuharth

Portland State University

Follow this and additional works at: https://pdxscholar.library.pdx.edu/open_access_etds

Part of the Bilingual, Multilingual, and Multicultural Education Commons Let us know how access to this document benefits you.

\section{Recommended Citation}

Neuharth, Jay Stanley, "Empowering ESL Students for Out of Classroom Learning" (1995). Dissertations and Theses. Paper 4909.

https://doi.org/10.15760/etd.6785

This Thesis is brought to you for free and open access. It has been accepted for inclusion in Dissertations and Theses by an authorized administrator of PDXScholar. Please contact us if we can make this document more accessible: pdxscholar@pdx.edu. 


\section{THESIS APPROVAL}

The abstract and thesis of Jay Stanley Neuharth for the Master of Arts in Teaching English to Speakers of Other Languages were presented May 10, 1995, and accepted by the thesis committee and the department.

COMMITTEE APPROVALS :

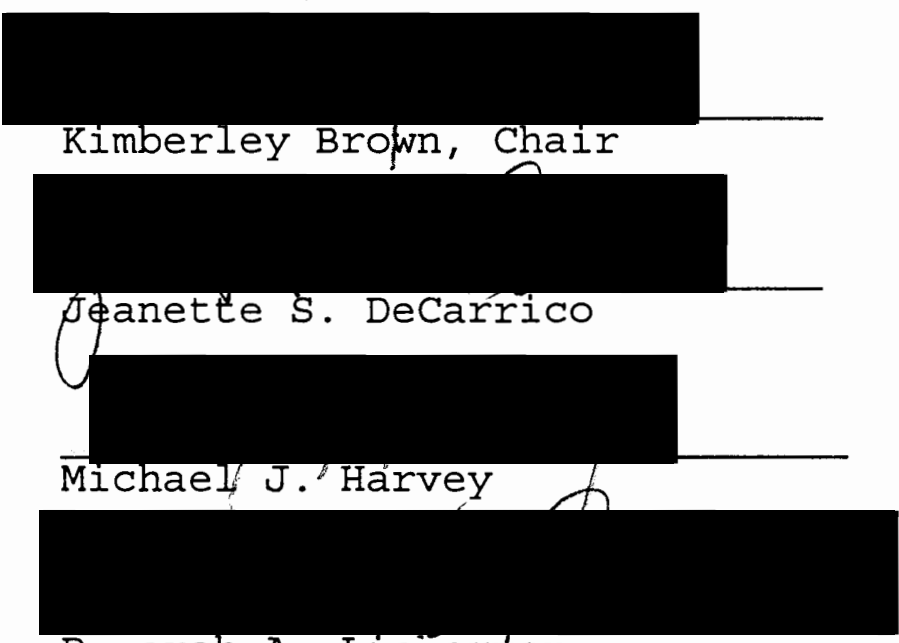

Devorah A. Lievermail

DEPARTMENT APPROVAL:

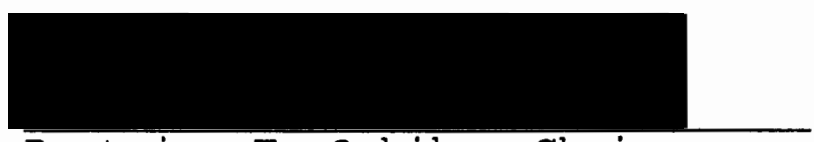

Beatrice T. Oshika, Chair

Department of Applied Linguistics

$\star$

ACCEPTED FOR PORTLAND STATE UNIVERSITY BY THE LIBRARY

by

on

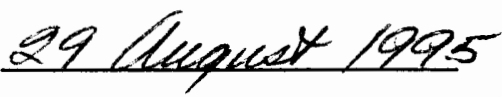


ABSTRACT

An abstract of the thesis of Jay stanley Neuharth for the Master of Arts in Teaching English to Speakers of Other Languages presented May 10, 1995.

Title: Empowering ESL Students for Out of Classroom Learning .

ESL students virtually swim in an environment rich in opportunities to learn English. Every billboard, newspaper, TV show, and person on the street provides new language. However, many ESL students do not take full advantage of this English environment. Often, English lear:.̇ng is viewed primarily as a classroom experience, when much more could be gained if students were learners outside the classroom, as well. That is the problem addressed in this thesis.

This problem was investigated through action research with the teacher/researcher's high intermediate level writing class at PSU. The teacher/researcher implemented a strategy to motivate students to learn outside the classroom which included student-generated language notebooks. Data recorded included: personal characteristics of the subjects, input on the language 
notebooks, instructor feedback on the notebooks, teacher's log, audiotaped student-teacher conferences and classroom discussions, and student surveys.

Analysis of the results revealed several promising techniques to motivate students to learn outside the classroom. A language notebook may be most effective if it includes a wide variety of input, including culture and record of the sources of entries. Furthermore, the notebooks should be given as extra credit, along with other options. In addition, student/teacher conferences were found to be effective to communicate the concept of out-ofclassroom learning and to elicit student opinions and suggestions. 
EMPOWERING ESL STUDENTS

FOR OUT OF CLASSROOM LEARNING

by

JAY STANLEY NEUHARTH

A thesis submitted in partial fulfillment of the requirements for the degree of

\section{MASTER OF ARTS}

in

TEACHING ENGLISH TO SPEAKERS OF OTHER LANGUAGES

Portland State University

1995 
DEDICATION

This thesis is dedicated to

my model as a teacher,

and as a person,

Jesus. 


\section{ACKNOWLEDGEMENTS}

I would like to thank Linda, my precious bride. She has freed me up to study while she invested in our most valuable work and joy: bringing up our children Autumn and Sierra. Linda, my thanks and respect for you know no bounds. 
TABLE OF CONTENTS

DEDICATION....................

ACKNOWLEDGEMENTS ...................

LIST OF TABLES....................

LIST OF FIGURES .................... vi

CHAPTER

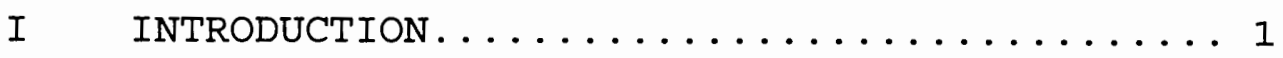

Background..................

Problem.................... 2

Research Question............. 5

Action Research............... 5

Explanation of Terms............. 10

II REVIEW OF LITERATURE............. II

Action Research................ 12

What is Action Research?

How is Action Research Done?

How Can Action Research Be

Reliable and Valid?

Student Motivation............. 23

What is Motivation?

How Does One Motivate Students?

Homework................... 26

Why Assign Homework?

How to Assign Homework?

Homework Evaluation and Feedback 


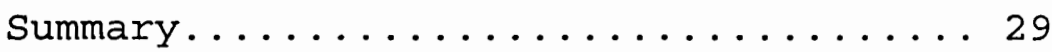

III METHOD ..................... 32

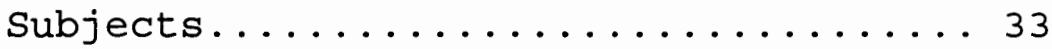

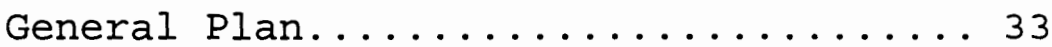

Monitoring/Data Collection ........ 35

Rethinking and Evaluation......... 37

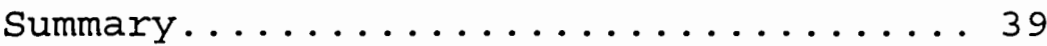

IV $\quad$ RESULTS......................... 41

Personal Characteristics...........4 41

Language Notebooks.............. 45

Instructor Feedback on Language

Notebooks................. 50

Teacher's $\log \ldots \ldots \ldots \ldots . \ldots \ldots 52$

Student $/$ Teacher Conferences........556

surveys....................660

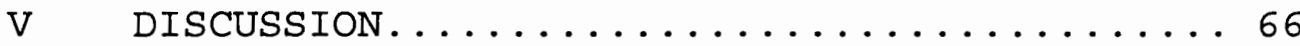

Evaluating the Intervention........66

Language Notebooks

Student Goal-Setting

Communication of Homework and Language Notebook Intent

Weekly Feedback

General

Conclusion and Revised General Plan... 78

Reflection

Revised General Plan

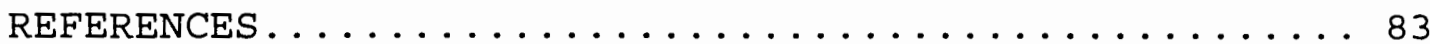

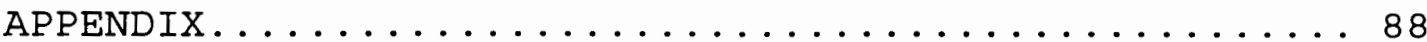




\section{LIST OF TABLES}

TABLE

PAGE

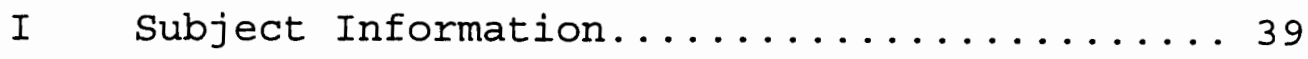

II Language Notebooks Quantity of Words....... 44

II Language Notebooks Class Total

Words Recorded............... 45

IV Survey Total scores................ 58 


\section{LIST OF FIGURES}

\section{FIGURE}

PAGE

1 Action research cycle (Kemmis, 1988)..... 6

2 Types of research (Van Lier, 1988)........ 15 
CHAPTER I

INTRODUCTION

\section{BACKGROUND}

In the winter term of 1994, I taught my first university-level English as a Second Language (ESI) classes. I was a practice teacher at Portland State University (PSU) in a high intermediate grammar class. Everything was fresh and new and I encountered something that changed by thinking about teaching.

The primary teacher for this class, Michael Harvey, was concerned that his students learn English not only during his classes, but outside the classroom as well. To encourage the latter, he required that the students in our class develop grammar notebooks, recording language they learned outside the classroom. Based on his own experiences as a language student and on observations as a teacher, instructor Harvey had implemented grammar notebooks with several classes before. The intent of these notebooks was that students would carry them with them throughout the day, jotting down new idioms, grammar structures, or other English that they were exposed to while living in an English-rich environment. 
Michael Harvey repeatedly urged the students to be alert to learn outside the classroom and to record what they learned in their grammar notebooks. This was done both verbally in class and in the individual written feedback. Four times through the term the notebooks were collected, graded, and the students given written feedback. I was involved in this evaluation, as well. Furthermore, grades on the notebooks were weighted to provide $1 / 4$ of the course grade. Despite these measures, the class response to grammar notebooks was disappointing.

Although a few students fulfilled the intent of Michael Harvey for the grammar notebooks, most did not. In most cases, the students used their grammar notebooks only sparingly for out-of-classroom learning. During this student teaching term, I had become convinced that out-ofclassroom learning is valuable, and that the grammar notebooks were a viable way to facilitate it. However, by the end of the term, it was clear to me that most students did not invest themselves seriously in the grammar notebook assignment. That surprised me and got me thinking.

\section{PROBLEM}

The problem is that students missed the opportunity for out-of-classroom learning via the grammar notebooks. Why? The argument for the importance of out-ofclassroom learning for ESL students is compelling. Comprehensible input and interaction in a second language 
results in learning (Krashen, 1981). Therefore, exposure to English in a natural setting, whether in or out of a classroom, results in learning. If the outside-theclassroom environment has potential to work in cooperation with the limited resources of the ESL classroom, it should be utilized.

In the ESL setting, opportunities for exposure and use of English abound outside the four walls of the classroom. There are innumerable inanimate sources: books, menus, theaters, bus guides, newspapers, magazines, TV, advertisements on billboards and bumperstickers, radio, and the internet. In addition, almost every person that walks by offers the potential of not only English exposure but also interaction. Forums to meet and talk with people include: churches, the post office, libraries, stores, banks, intramural sports and clubs, restaurants, neighbors, host families, language partners, fellow-employees, and community classes. ESL students live 24 hours a day in an ocean of English.

If students limit their learning English to the ESL classroom, they cut off the majority of their potential language input and interaction. That, in turn, can limit their language learning. Certainly, much English learning takes place in ESL classrooms; however, the classroom at its best is also a catalyst for outside-the-classroom learning. However, many ESL students do not take full advantage 
of learning outside the classroom. Contributing to this situation is the lack of perception of the value of out-ofclassroom learning. Due to cultural parameters from their own schooling, many ESL students consider the teacher to be the primary one responsible for their learning and the classroom to be the primary place for it. Often, students are content to learn ESL merely by coming to class, doing the assignments, and studying for the tests.

Because of the value of out-of-classroom learning, it is appropriate to try to understand it better. To do so, some practical means of assessing students' investment in outside-the-classroom learning is needed. Drawing from Michael Harvey's concept of grammar notebooks, a studentgenerated language notebook can serve as an indicator of out-of-classroom learning.

Language notebooks are a place for students to record what they are learning outside the classroom. Certainly there is much that students may learn outside the classroom that a language notebook cannot capture. Nevertheless, such a notebook assigned to students for the very purpose of recording out-of-classroom learning can provide an indicator of that learning. Other indicators and observations are also in order. 
RESEARCH QUESTION

After considering the problem I encountered in Michael Harvey's class, it seemed best to address the following research question:

What will empower ESI students to formalize and expand their out-of-classroom learning?

The intent here was to seek, by various means, to overcome any hinderances and empower students to learn more outside the classroom. The research question was open-ended in order to facilitate creativity and responsiveness to the students during the term. All students are not alike; therefore, some may respond differently than others. This question guided me through the research process.

\section{ACTION RESEARCH}

Because the research question above is open-ended, it required a research process that allowed such broad boundaries. Furthermore, as mentioned above, several indicators and types of observation would be useful in considering students' out-of-classroom learning. The research format needed to include rich, rather than narrow, data. Finally, the lack of student investment in out-ofclassroom learning was an actual problem in my class, so I desired to tackle it with my students directly. For all 
those reasons, the necessary and sufficient format was action research.

Action research involves the teacher as researcher in an iterative cycle, as portrayed in Figure 1. 


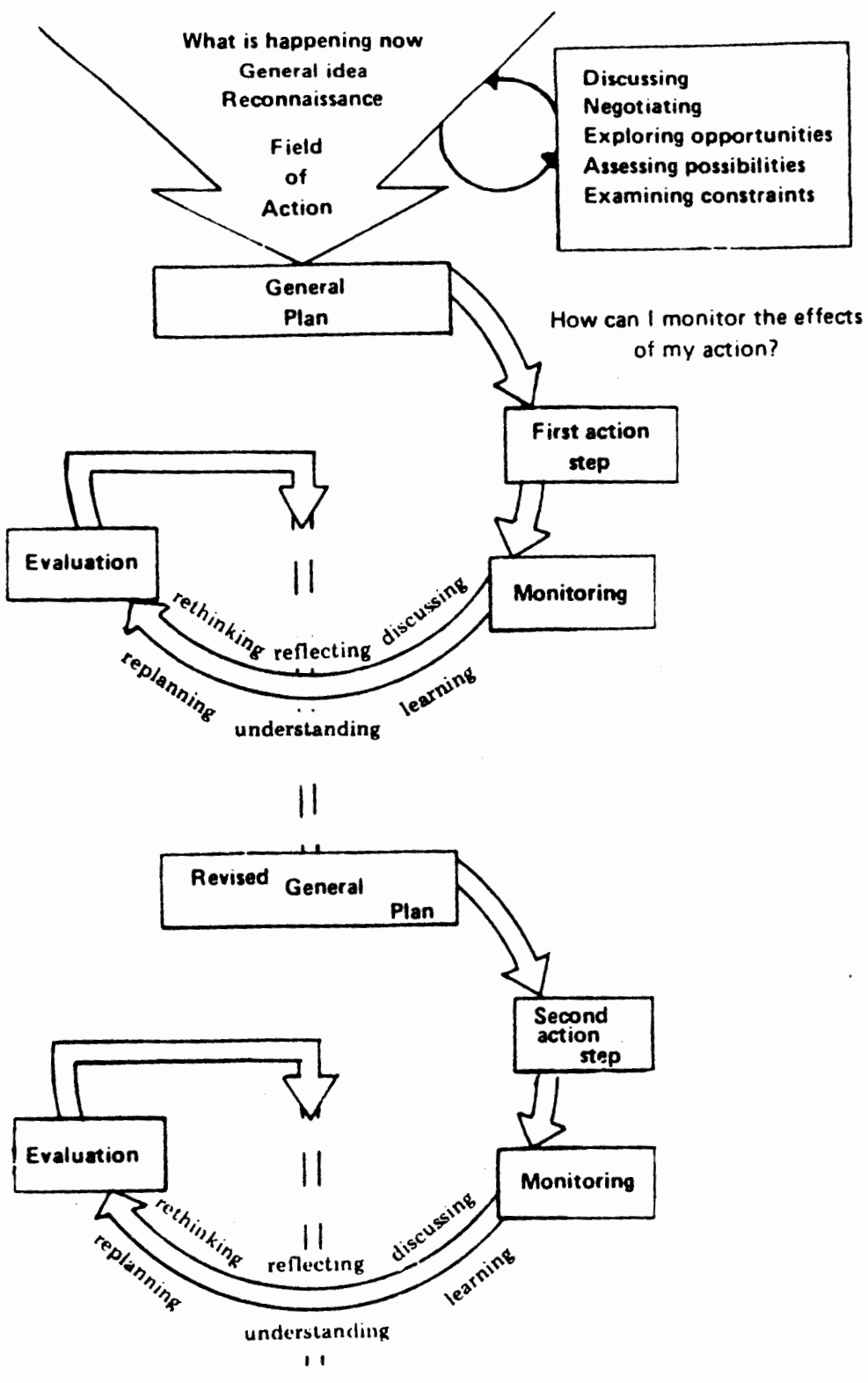

Figure 1. Action research cycle (Kemmis, 1988).

Although a full introduction to action research is reserved for Chapter II, a brief examination of the steps involved is provided below. At the beginning of the action research cycle is a practical classroom problem, "What is happening now." Through exploration of this problem and potential stragies to address it, a general plan is developed. This 
plan is then implemented with an action step and the effect of this action is monitored. Vital to this process is the rethinking, reflecting, discussing, replanning, understanding, and learning that occur throughout. Then, there is an evaluation, which spawns a revised general plan for implementation in the next iteration of the process. In this thesis, I undertook one full cycle of this process and carried it to what is listed in Figure 1 as Revised General Plan. The scope of this research included monitoring, reflection, and evaluation. My problem was expressed in the research question, "What will empower my students for out-of-classroom learning?" After exploration of possibilities, constraints, and opportunities available to me, I settled on a general plan, which is laid out in Chapter III. That plan called for a strategy to empower my students to formalize and expand their out-of-classroom learning. My strategy included:

a. Promoting the use of a student-generated language notebook to record out-of-classroom learning;

b. Goal-setting with individual students during student/teacher conferences early in the term;

c. Clear and specific on-going communication of homework asignments and the intent of the language notebook;

d. Weekly feedback on language notebook entries. The effects of this strategy were monitored via several types of data, the results of which are found in Chapter IV: 

a. Personal characteristics of the subjects;
b. Language notebooks themselves;
c. Instructor feedback on Language Notebooks;
d. Teacher's Log;
e. Audiotaped student/teacher conferences;
f. Student surveys.

This data was examined via rethinking, reflecting, discussing, with an aim to understand and learn about what might empower these and future students for out-of-classroom learning. To complete the action research cycle, I evaluated the findings to draw conclusions and form a revised general plan for the next iteration. Chapter $V$ discusses this rethinking, reflecting, and evaluation. Explanation of key terms for this thesis follows. 


\section{EXPLANATION OF TERMS}

Action Research: A mode of research in which the teacher initiates, conducts, and analyzes the data. It is concerned with affecting change via an iterative cycle of action, motoring, rethinking, evaluating, and revised plan of action.

Language Notebook: A student-generated record of out-ofclassroom learning.

Out-of-Classroom Learning: Acquisition of language or other knowledge or wisdom not accomplished during class time.

Theory of Personal Investment: A theory of motivation centering on two ideas: "I) People invest themselves in certain activities depending on the meaning these activities have for them; and 2) Meaning involves three interrelated categories of cognition: personal incentives, sense of self, and perceived options." (Renchler, 1991, p24, with credit given therein to Maehr and Braskamp).

Goal-Setting: Teacher and individual students together establishing personal student objectives for performance at the beginning of the term.

Student Investment: Effort, time, energy, and attention put in by students in out-of-classroom learning. 
CHAPTER II

REVIEW OF LITERATURE

\section{INTRODUCTION}

The thesis at hand involves three areas: action research, student empowerment, and out-of-classroom learning. Action research history, theory, and principles must be investigated in order to effectively apply this research format. Secondly, student motivation is crucial to empowerment, so the literature of student motivation should be examined, as well.

Finally, the aim of the motivation in this thesis is out-of-classroom learning. The researcher found it beneficial to extend the field of out-of-classroom learning to the topic of homework, even though the two terms are by no means synonymous. "Homework" has a connotation of teacher-directed assignments, whereas "out-of-classroom learning" includes a much broader spectrum of learning opportunities.

The literature on homework was reviewed to access previous research. This was especially important because few literature sources could be found specifically in the non-academic area of out-of-classroom learning. However, 
homework, a traditional academic exercise directed outside the classroom, has a rich literature basis. Therefore, it was necessary to augment the background for this thesis by an examination of homework.

The three areas chosen for this literature review, then, are: action research, student motivation, and homework. Although there are certainly other potential areas of literature review which might be beneficial, these three are the most critical, and thus are sufficient for the scope of this thesis. Other potential fields of study would include: cross-cultural communication, learning style differences, and cultural distinctives lespecially for the cultures represented in the subjects).

\section{ACTION RESEARCH}

This section is organized to answer the following questions in sequence. What is action research? How does one do it? and How can such research be reliable and valid?

\section{What is action research?}

Action research is an iterative spiral of research conducted by teachers with their own students as subjects. Each cycle of the spiral involves the teachers/researchers developing a general plan of intervention to address a problem. They act on that plan, monitor its effects, reflecting a evaluating, and formulate a revised general 
plan to try in the following cycle of research. The teachers/researchers investigate specific problems they encounter with the intent of changing them -- it is not enough to merely understand; change is essential (Nunan, 1992). The concern of the researcher is primarily with the classroom problem and the students at hand, rather than with generalizable findings.

While action research can be done by one teacher alone, working together with other teachers is preferred. Some authors, such as Oja \& Smulyan (1989), consider collaboration with peer teachers and other faculty as a defining characteristic of action research. Furthermore, action research involves the subjects in its formulation and execution (Kemmis, 1988).

Features of action research include:

...it is situational, or context-based, collaborative in that researchers and practicioners work together, participative, since team members themselves implement the research, and self-evaluative, i.e: based on the ongoing evaluation of improvement achieved. (van Lier, $1988: 67-8$ )

While action research is popular today, it is not a new idea. McFarland and Stansell (1993) trace the roots of action research back to Aristotle in the fourth century $B C$, who promoted the observer's role and morally informed action. Closer to the present, Maria Montessori (1870 1952) experimented in school settings and trained teachers in observation. 
Action research as a qualitative form was promoted in the 1940's by Kurt Lewin. Lewin advocated it as a way to address social problems. Then, in the 1950's, Stephen Corey and Abraham Shumsky boosted action research as a way to improve, teachers' practice (Nixon, 1981).

Oja and Smulyan (1989) report that the phase of purely scientific research earlier this century was followed by a pessimistic phase in which scientific research was viewed as irrelevant to education. Then, in the past fifteen years, a new self-reflective phase has emerged. In the main artery of this phase runs action research, in which the teacher is the researcher.

These are samples out of the history of the action research concept. They show that the idea of teachers being researchers, like most quality ideas, is not new. Improving teachers have always taken advantage of their daily opportunity to be investigators. Therefore, the action research of this thesis draws upon a long-standing tradition. In action research, theory and practice are integrated (Kemmis, 1988). The approach is very different from scientific research, in which theoretical propositions are investigated via carefully controlled and structured experiments. In action research, proposals of theory are investigated via practicing them. Compared to experiments, surveys, observations, and other types of research, action 
research is high in control and low in structure, as depicted in Figure 2 .

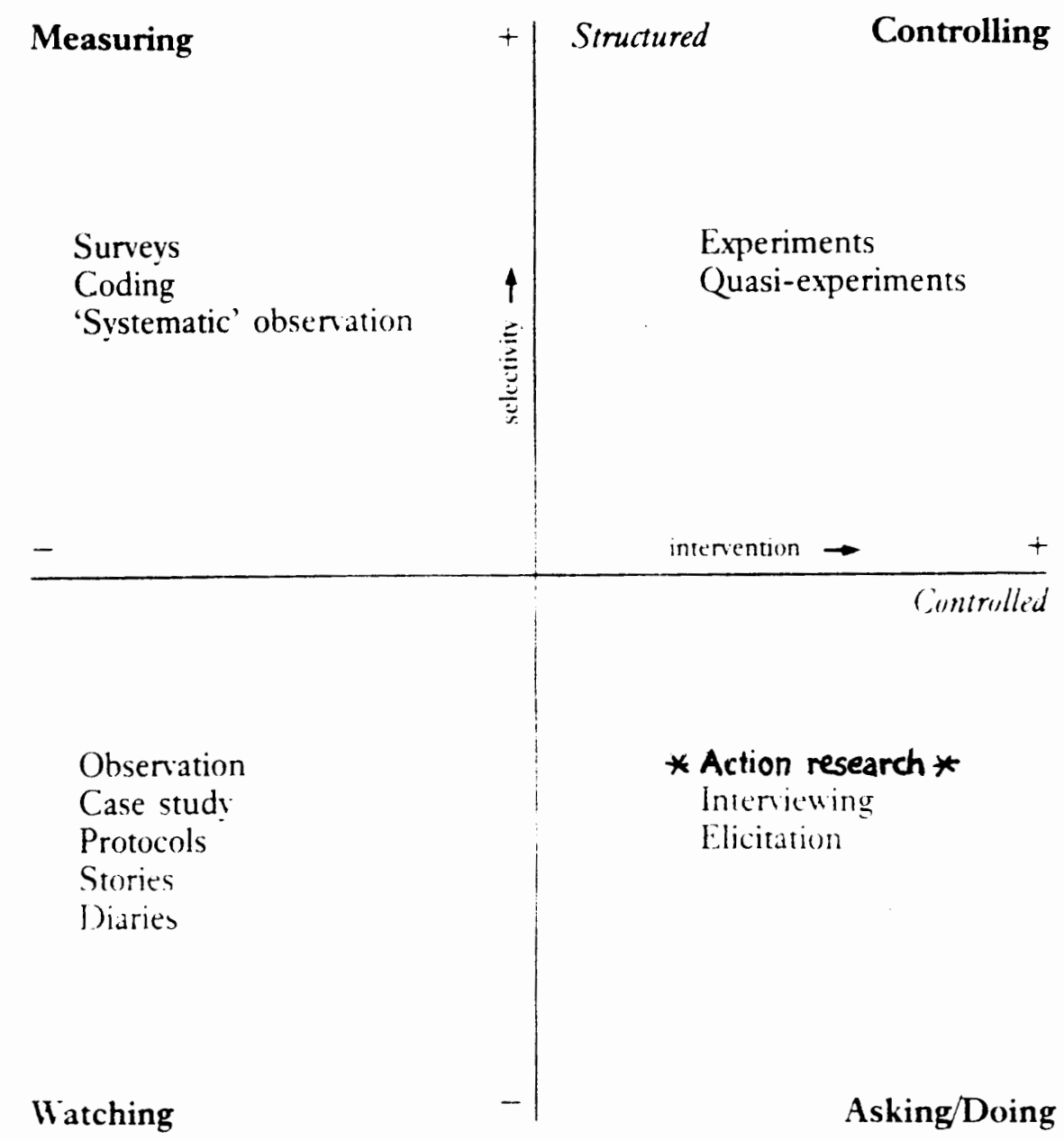

Figure 2. Types of Research (Van Lier, 1988).

Action research is balanced. Its approach to education research combines both the scientific and interpretive views (Carr and Kemmis, 1986). Action research is interpretive in that it seeks to study from the point of view of the 
practitioners. Nevertheless, action research is also scientific in the sense that the theories generated provide a rational challenge to the concepts and theories already practiced and believed by the practitioners.

Key to action research is that the teacher/researcher is an insider (Nixon, 1981). As insiders, teachers are in a unique position to observe schooling -- they are present in the classroom every day. Furthermore, teachers are uniquely adept at disseminating findings to other teachers, because they are their peers.

\section{How is Action Research Done?}

The spark that starts the process of action research is simply a teacher with a problem. Elliott (1978) writes that "the aim of action research is to deepen the teacher's understanding (diagnosis) of his problem." That problem is addressed via fact-finding, discussion, planning and execution of that initial plan, evaluation and formulation of a revised plan, execution of that, evaluation ... a spiral of this cycle (van Lier, 1988).

The specific stages of action research are described somewhat differently by different authors, but the spiral process depicted in Figure $I$, page 6 , is consistent. One author, Nunan (1992), identifies the following seven steps, which represent the mainstream of the literature: 
1. Initiation. A teacher wants to address a classroom problem, to improve learning in his classroom.

2. Preliminary investigation. The classroom is observed and baseline data are recorded.

3. Hypothesis. The teacher, perhaps working with other faculty, hypothesizes the cause of the problem.

4. Intervention. A number of strategies to address the cause of the problem are planned and carried out.

5. Evaluation. The class is observed again, to see if the intervention improved the problem.

6. Dissemination. The teacher runs a workshop for peer teachers locally and presents a paper at a conference.

7. Follow-up. The teacher investigates alternative methods of addressing the problem.

These steps form a scaffold for the following discussion. Inherent in action research is its iteration (see step 7 above). One idea is tried in the classroom, the effects are considered, then that new information contributes to a new idea, which is then tried, and so on.

Several authors stress the value of collaboration in action research (see step 3 above). Nixon (1981) says that action research should, from the start, involve other teachers, administrators, and even a cross-curricular team.

Although action research addresses directly the specific problem of one teacher, dissemination of findings to other teachers is part of the process (see steps 1 and 6 
above). Nixon (1981) says it is important to pass on what is learned by action research projects not only to local peer teachers, but to a broader range of teachers, as well. He further suggests that the research report should be adjusted to meet the needs of the recipients (i.e. For teachers to read it, it should be short).

The foregoing list of steps notwithstanding, there is no one way to do action research. The specific method and process in a certain situation depend on the skills of the teacher, the nature of the problem, and the resources available (Nixon, 1981).

Oja and Smulyan (1989) identify four forms of action research: 1) "Teacher as Researcher," in which the teacher engages in reflection, planning, and action; 2) "Experimental Social Administration," which aims at policy change through taking an outside-research-based hypothesis and testing it in a classroom; 3) "Simultaneous-Integrated Action Research," in which teachers are involved in the planning, but the initial idea comes from outside; and 4) "Collaborative Action Research," in which a group of teachers, administrators, and faculty work together on all parts of the process. Forms 1) and 4) are the most consistent with Nunan's idea of action research; nevertheless, potential solutions to a teacher/researcher problems may certainly originate outside the teacher. 
Pursuing form 4) above, Mohr and MacLean (1987) describe on-going collaborative action research. Working with $\mathrm{K}-12$ teachers in northern Virginia, the teacher/researcher group meets throughout the year. They collect data every fall, and analyze them in spring. Training, discussion, and support occur in group meetings. New teacher/researchers are trained to write free-form research logs, the first of them field notes. Their initial questions in the logs are developed into research questions. Overall, this is a valuable model for collaborative action research.

The rest of this section will follow the framework of Nunan's first five steps above.

The foundation for an action research project is choosing research questions (see steps $1-3$ above). The teacher/researcher has a great deal of freedom in framing the questions, to address his specific needs and interests (Mohr and MacLean, 1987). Goswami and Stillman (1987) suggest beginning with the widest, wildest possible range of questions and looking for recurring themes. Those themes can be boiled down to the actual research questions.

In addition, the research questions may change as the study progresses, based on new data (Nixon, 1981, pI4). Therefore, Hubbard and Miller (1993) recommend keeping the initial research questions open-ended (i.e. not yes/no) to allow for possibilities to emerge. In addition, Eisenhart 
and Borko (1993) urge teacher/researchers to keep an ethnographic perspective. That is, one should choose questions and method of data collection bearing in mind that the researcher is a participant (not an observer only) in a prolonged study.

Regarding conducting the research (see step 4 above), Peter Medway has said "the hardest bit is making the familiar classroom strange to yourself" (quoted in the preface of Goswami and Stillman, 1987). Although the researcher is a participant, a certain skill of keeping distance for perspective is necessary (Mohr and MacLean, 1987). There is also the related issue of how much to inform the students of the research. Pam Reed, an experienced action researcher, tells her students at the beginning of the term something of what she will be observing, and then does not mention it anymore (Goswami and Stillman, 1987, p 127).

The practical methods of data collection (step 5 above) can be varied. Nixon (1981) suggests several, including tests, attendance, marking written work, and informal talk with other teachers about pupils. He encourages the teacher/researcher to find a method which includes crosschecking (multiple overlapping data collection modes) and which best fits the teacher's schedule and time-commitments. Van Lier (1988) holds that, even in a participant 
observation context, qualitative data can substantially suppliment qualitative data.

How Can Action Research Be Reliable and Valid?

Because of the varied forms which action research takes, and due to the continual development of the research questions and methods, it may appear unrealistic to ask for reliability and validity. However, several authors state to the contrary.

Action research joins other research in the need for reliability and internal validity (Nunan, 1992). Internal reliability is the need for consistent collection and analysis of data. In addition, external reliability is the lack of researcher bias -- would another researcher get the same results? Because of the strong relationship which exists between teachers and their classes, it is a challenge in action research to achieve external reliability. This involves the issue of generalizability of the results from samples to populations. Nunan (1992) holds that external validity is not crucial in action research because the primary purpose of teacher/researchers is to solve specific problems in their classrooms.

Internal validity involves the interpretation of the research. Nunan (1992) asks "Can any differences which are found actually be ascribed to the treatments under scrutiny?" Action research analysis must consider 
alternative factors and be objective in reaching conclusions.

In fact, teacher/researchers, who face unique challenges and dangers, must maintain standards in order to produce valuable results. Therefore, because traditional definitions of validity and reliability are not sufficient, Eisenhart and Borko (1993) propose the following standards of validity specifically for action research:

1) Contribution to knowledge in the field; how does this research fit in the broader field of research?

2) Fit between the research questions and data collection and analysis procedures; do the research questions drive the data collection procedures?

3) Effective application of data collection and analysis techniques

4) Value constraints:

a) External Value -- What value might the findings have for practical use or further research; "So what?"

b) Internal Value -- how are the subjects treated? With confidentiality and respect?

5) Comprehensiveness:

a) (Regarding Standards 1-3) Overall contribution, clarity, coherence, and competence of the study and its conclusions

b) (Regarding Standards 1-4) Balance of the value and risks of the study 
c) Being able and alert to consider wide fields of knowledge and other possible explanations of the results

Related to 5 c) above, Eisenhart and Borko (1993, pp 41-48) urge teachers/researchers to consider the "culture" of the classroom, including the immediate learning environment, the social system surrounding the school, and the individual within the class. The problems and solutions are not as simple as may sometimes appear.

Before leaving the discussion of validity, it is crucial to note the participatory nature of action research. $\checkmark$ Teacher/researchers are actively involved with both colleagues and students/subjects. Elliott (1988) makes this statement: "Since action research looks at a problem from the point of view of those involved, it can only be validated in an unconstrained dialogue with them." This point underscores the sharp distinction between action research and scientific experimentation, in which such a concept of validity would be irrellevant.

\section{STUDENT MOTIVATION}

This section is organized to answer these questions, in sequence: What is motivation? and How does one motivate students?

What is Motivation? 
"Motivation is that which gives direction and intensity to human behavior" (Frymier, 1985, p 6). Various educators view motivation in several ways (Renchler, 1991). It can be seen as a personal trait for the long term or as a temporary response to situations (e.g. an individual student motivated for one task and not motivated for the next task). In addition, the individual's concept of self affects motivation. Wlodkowski (1978) stresses that any number of things can ruin a student's motivation. In short, the concept of motivation is complex!

Most authors consider motivation to be changeable. For instance, Grossnickle (1989) emphasizes that students can learn to be self-motivated to achieve. In his view, motivation is not primarily an unchanging trait, but it can be improved through training and practice.

The Theory of Personal Investment (Renchler, 1991) $\mathrm{V}$ offers a workable explanation of motivation. According to this theory, people invest themselves personally depending on the meaning these activities have for them. Meaning involves three interrelated categories of cognition: personal incentives, sense of self, and perceived options. Therefore,

for ESL students to be motivated to learn outside the classroom, they must first see the meaning of learning outside-the-classroom as a whole.

How Does One Motivate Students? 
Before delving into techniques recommended to increase motivation, hindrances shall be mentioned here. Gonder (1991) says that the following factors keep students from succeeding: teachers' low expectations, passive learning, and over-extended teachers. Furthermore, Raffini (1988, p 7) stresses that norm-referenced evaluation decreases motivation in most students because self-worth is at risk. For example, average-performing students may be repeatedly reminded that they are not as good as some of their peers. only a few can succeed in norm-referenced evaluation, so many students become apathetic to avoid failure.

The most consistent way to increase motivation mentioned in the literature is goal setting. Frymier (1974) emphasizes making goals and objectives which are clear and generated from student concerns. Grossnickle (1989) concurs, "Ideally, the student and teacher develop a plan." Grossnickle also urges teachers to be realistic in setting goals and standards. Therefore, this thesis included student goal-setting as a strategy to motivate.

Furthermore, it is important to be alert to the differences in students:

A wise man once observed that a great many children are like wheelbarrows: not good unless pushed. Some are like canoes: they need to be paddled. Some are like kites: if you don't keep a string on them they fly away. A few are like a good watch: open face, pure gold, quietly busy, and full of good works. (Mandel, quoted in Grossnickle, 1989, p20) 
One seeking to motivate students should be patient with the wheelbarrows and canoes, taking students as they are (Gigous, 1974).

Many other suggestions for motivating students are made, including: cooperative learning (Raffini, 1988), praising (Johannesson, 1967), organization (Grossnickle, 1988), outcome-based evaluation (Raffini, 1988), building student ownership and discouraging dependency on the teacher (Grossnickle, 1988), a pleasant learning atmosphere, humor, and letting students have a say (Lloyd, 1986).

Many of these techniques are profitable in the ESL classroom. In recent years, for example, many language teachers have emphasized a learner-centered approach. Learner styles, needs, and expectations are taken into account. Students even have a hand in developing curriculum in many programs.

\section{HOMEWORK}

This section is organized to address the following questions regarding homework: Why assign it? How to assign it? How to evaluate and give feedback? 
Why Assign Homework?

Homework is defined by Cooper (1989, p 7) as "tasks assigned to students by school teachers that are meant to be carried out during non-school hours." Cooper goes on to describe two general categories, practice homework and extension homework. Practice homework reinforces skills learned in school by repetition, while extension homework transfers what is learned in the classroom to new situations outside of school. For ESI students, both types of homework are valuable.

The primary benefit of homework is increased learning by students. Research cited by England (1985) supports the conclusion that homework improves student performance. In addition, Doyle (1988, p 20) says that homework can be useful to promote learning.

Homework in language learning is especially appropriate. Brewster states "Normal language acquisition is a social rather than an academic activity" (1983, p viii). Therefore, interaction among people during the many hours of each day outside the classroom would contribute greatly to language learning. Papandreou (1991) lists several benefits of homework in the EFI classroom, including: extra time devoted to learning English, development of self-discipline, opportunity to work at individual pace, consistent work in English, and involvement in learning tasks non-existent in a classroom. 
The benefit of homework in an ESI class can be beyond English language. Laconte (1981) proposes that teachers make the aim of all homework learning how to learn, not merely preparation or practice. This is close to the heart of out-of-classroom learning - an attitude of learning everywhere.

How to Assign Homework

A key to assigning homework is making it clear and specific (Papandreou, 1991). Homework should be announced in advance, as well. For most students in an ESI setting, the more clear the explanation, the better.

Laconte (1981) stresses that teachers should be careful of students' time demands, especially when several teachers are giving assignments to the same student. He goes on to say that homework should emphasize student initiative and freedom, be as individualized as possible, and require imagination and creativity. Therefore, a balance should be maintained between structure and creativity in homework assignments.

Brewster (1981) proposes that out-of-class learning be planned by students. In a study by olympia (1992), performance goals set by the students improved their accomplishments. However, accuracy goals were more effective if set by the teacher. 
Students can also keep track of their homework. Papandreao (1991) suggests students entering homework in a course exercise book, continuing for the term. This is another aspect of students participating in the homework curriculum. Furthermore, journaling can both provide a convenient place for homework assignments and help record research data and decision-making by students and teachers (Carrol1, 1994).

Homework Evaluation and Feedback

The main criterion for evaluating homework is not accuracy but the exhibition of willingness and consistency to work and learn (Papandreou, 1991). This can be determined best if checked on a regular basis. Shockley (1969) recommends diagnosing homework daily and keeping records of student completeness.

Students look carefully at what teachers mark on their homework. Gerngross and Puchta (1992) suggest that editing, rather than plain correction, is useful. Then students can prepare a new version.

SUMMARY

Authors such as Nunan (1992), Carr and Kemmis (1986), and Eisenhart and Borko (1993) provide a background for action research. Action research draws upon the tradition of teachers being also researchers which traces its roots back to Aristotle and has enjoyed blossoming in recent 
years. The basic process of action research today involves teacher/researchers addressing a specific problem in their own classrooms, via an iterative investigation and trial process. Nunans seven steps are representative of the action research process.

Frymier (1974, 1985), Grossnickle (1989), and Renchler (1991) are key authors on the area of student motivation. One key to motivation is that students see the meaning for the activity. While norm-referenced evaluation may hinder motivation in most students, student goal-setting helps to generate student investment. In addition, developing a learner-centered atmosphere boosts student motivation.

Homework, and out-of-classroom learning in general, give increased opportunity to learn. Literature in this field includes such authors as Cooper (1989), LaConte (1981), and Papandreou (1991). One object of homework should be learning how to learn, not merely preparation or practice. Furthermore, out-of-classroom learning is best accomplished when students have a hand in planning it and keep a record of it. Nevertheless, students' time demands should be taken into account when assigning homework, and a balance should be maintained between structure and creativity.

There is much to be gained from the literature on action research, student motivation, and homework. Little 
research has been published, however, which focuses on motivation for out-of-class learning for aduIt ESL students. 
CHAPTER III

METHOD

This thesis was conducted following the guidelines and principles of action research. The researcher was concerned with the students in his upcoming I3 Grammar class. Furthermore, the primary intent of this project was to empower them to formalize and expand their out-of-classroom learning. The steps involved in this thesis followed roughly those identified by Nunan (1992). They represent one and a half cycles (see Figure I) of the action research process, including a revised general plan.

1. Teacher/researcher identified the problem and developed research questions and a general plan of intervention.

2. Intervention -- Teacher/researcher tried various means of empowering his students to formalize and expand their outside-the-classroom learning.

3. Data analysis and rethinking -- data recorded during the intervention step was analyzed and reflected upon throughout the process.

4. Dissemination - - teacher/researcher passed along his initial findings. 
5. Follow-up -- teacher/researcher laid out a revised general plan to follow-up the initial findings with future classes.

\section{SUBJECTS}

The subjects were the students in the researcher's high intermediate level grammar class, Fall of 1994. They were seven adult students, from Japanese, Thai, and Taiwanese backgrounds.

All students in this class voluntarily participated in the research, and signed consent forms approved by the Human Subjects Review Committee. All subjects have been given pseudonyms in the results and conclusions of this thesis.

There are two major limitations of this thesis. First, because the sample size is small, only seven subjects, the results cannot be generalized to any other group with confidence. Second, because there is no control group, the determination of causation cannot be scientifically concrete. However, those are common limitations in action research (Nunan, 1992).

\section{GENERAL PLAN}

The following four steps comprise the researcher's general plan to empower his students to to formalize and expand their out-of-classroom learning: 
a. Promoting the use of a student-generated language notebook to record out-of-classroom learning.

b. Goal-setting with individual students during student/teacher conferences early in the term.

c. Clear and specific on-going communication of homework assignments and the intent of the language notebook.

d. Weekly feedback on language notebook entries.

The first week of classes, Fall 1994, was a crucial week for this thesis. The researcher explained the concept of out-of-classroom learning and a language notebook to his students, as well as invited them to participate in the thesis and consider the consent form.

Also during the first weeks, he met with each student individually. The students were assigned the task, prior to the meetings, of considering a personalized format for their own language notebooks. During the individual meetings, the teacher/researcher helped the students to organize their language notebook and set personal goals for out-ofclassroom learning. These goals were recorded by the teacher. The teacher/researcher sought to answer any questions and put the students at ease about this learning format, which was new to some of them.

The teacher/researcher advocated the concept of out-ofclassroom learning throughout the term. Just over half-way through the term, a second reound of student/teacher 
conferences were conducted. In these, the teacher/researcher elicited student feelings, opinions, and suggestions related to the language notebooks. In addition to promoting self-initiated entries in the language notebook, the teacher occasionally assigned out-of-classroom homework to be completed in the language notebooks. Throughout the term, language notebooks were collected each week. The number of new entries were recorded by the researcher, including whether it was self-initiated or in specific response to an assignment. The teacher then returned the language notebooks, with written feedback, to each student.

During the last week of the term, the teacher/researcher administered a survey to his students (See Appendix). This survey asked both open- and closedended questions about the various strategies for motivation employed during the term.

In addition, a teacher's log was kept by the researcher. In it, he recorded his observations of students, both during class and outside of class, in freeform style.

\section{MONITORING/DATA COLLECTION}

To monitor the effect of the above strategy, several types of data were collected, including both quantitative and qualitative. The primary tool for collecting 
quantitative data for this thesis was the students' language notebooks. Out-of-classroom assignments (except exercises from textbooks) were recorded in the notebooks by the students. The language notebooks were collected and reviewed by the researcher each week. He recorded every student attempt at out-of-classroom learning, noting the length and whether it was self-initiated or strictly in response to a specific assignment.

The number of words written in language notebooks is an indicator of student investment in out-of-classroom learning. Students were instructed to look for opportunities to learn English outside the classroom, and assigned language notebooks to record and formalize it. Therefore, while a written record cannot capture $100 \%$ of students' out-of-classroom learning, it is a fair indicator of student investment. Thus, student' entries in their language notebooks form one aspect of monitoring the effects of the intervention in this thesis.

In addition, a written survey (see Appendix) was given to all subjects at the end of the term. The intent of the survey was to learn students' opinions on the effectiveness and desirability of the strategies employed.

The final type of quantitative data collected was the personal characteristics of each student. Age, sex, and nationality were recorded at the beginning of the term. 
The qualitative data were important for this thesis. The first qualitative technique of data collection was a teachers' journal. The teacher/researcher kept a free-form journal. This was intended to record his observations of students both in and out of class.

Qualitative data were also collected in the form of audio recordings and written instructor feedback. All student/teacher conferences were audiotaped, as were portions of a few class discussions. Also, the weekly language notebook feedback from the researcher to each student was copied.

In addition, the researcher collected insights and data from informal discussions with another instructor, Michael Harvey. Professor Harvey also implemented a language notebook in his high intermediate reading/writing class. Most of the subjects of this thesis were also in Professor Harvey's class.

The qualitative data from the language notebooks form the core of the results of this thesis. That core is better augmented by the quantitative data.

\section{RETHINKING AND EVALUATION}

Throughout this thesis process, the foregpoing data were analyzed, thought through, and discussed. This resulted in insights gained along the way, which are presented in Chapter III. Evaluation led to the formulation 
of a revised general plan, for implementation in follow-up action research.

In addressing the research question, the researcher had to bear in mind that the individual parts of his strategy to empower students (e.g: language notebooks, goal-setting, ongoing communication, etc.) work together. Therefore, the specific contribution of each individual aspect of the strategy would be hard to determine. That would have been beyond the scope of this thesis, although some insights about individual techniques were discussed. However, analysis of the data yeilded evidence as to whether or not the combination of strategies employed during the term were successful. That is sufficient for the purpose of the researcher.

Qualitative data were collected in the survey, the teacher's log, the audiotapes, and feedback notes. Student responses to closed-ended questions in the survey were tallied and analyzed to determine consistent feelings. In addition, those responses were checked to see if there were any common feelings among subgroups (e.g: males or females, ethnic groups, etc.).

The teacher's $\log$ and audiotapes were scanned for observations pointing toward student motivation. The researcher looked for remarks on verbal or non-verbal signs of student interest or lack of it. In addition, the language notebook feedback notes were examined for 
connections between specific comments and subsequent student performance.

To round out the analysis, the researcher reviewed the open-ended questions on the surveys and. No strict mode of analysis was applied. Rather, the researcher looked for recurring themes which might shed light on the thesis.

In analyzing this data, the researcher maintained a critical perspective. Conclusions were made with caution, considering alternative causes of the results. In a study such as this one, with a sample of seven, often the best conclusions are proposals and suggestions which can be looked into further.

\section{SUMMARY}

This thesis involved dynamic teacher/researcher work with seven international students at P.S.U. in the Fall of 1994. The researcher tried to empower students to formalize and expand their out-of-classroom learning by several techniques of intervention: promoting the use of studentgenerated language notebooks, goal-setting with individual students, on-going communication of the concept of out-ofclassroom learning, and weekly feedback on language notebooks.

The students were monitored to evaluate the effects of this intervention strategy. Monitoring data included: student entries in their language notebooks, personal 
information on each subject, the teacher's log, audiotapes of student/teacher conferences and some class discussions, teacher feedback to students about their language notebooks, and a term-end survey eliciting students' opinions and perceptions. 


\section{CHAPTER IV}

\section{RESULTS}

The results collected from this thesis are in many varied forms. First there are the personal characteristics of the individual subjects. Second, the contents of the subjects' language notebooks are included, including tabulations of the number of words recorded. Third, there is the instructor/teacher's feedback to the students about their language notebooks. Fourth, exerpts from the teacher's log contribute to the results. Fifth, student/teacher conferences and in class discussions are recorded on audiotape. Finally, the student surveys from the end of the term provide data, as well. These results follow in turn.

\section{PERSONAL CHARACTERISTICS}

These seven subjects studied were in the researcher's Level 3 Grammar class in the Fall of 194 at PSU. They came from three Asian countries (Japan, Thailand, and Taiwan) and each carried a student visa. There were four females and three males in the class, ranging from 20 to 27 years of age. Their personal characteristics are summarized in the Table I. 


\section{TABLE I}

SUBJECT INFORMATION

$\begin{array}{lcclc}\text { Name* } & \text { Sex } & \underline{\text { Age }} & \text { Country } & \text { Course Grade } \\ \text { David } & \text { M } & 27 & \text { Thailand } & \text { B } \\ \text { Hirai } & \text { M } & 20 & \text { Japan } & \text { D } \\ \text { Jude } & \text { F } & 22 & \text { Japan } & \text { A } \\ \text { Kei } & \text { M } & 20 & \text { Japan } & \text { B } \\ \text { Momiko } & \text { F } & 25 & \text { Thailand } & \text { A } \\ \text { Shiroe } & \text { F } & 22 & \text { Japan } & \text { Pass } \\ \text { Yik Cheng } & \text { F } & 25 & \text { Taiwan } & \text { B } \\ \text { *Pseudonyms } & \text { are used in place of actual names. }\end{array}$

Each of these students had different backgrounds, future education plans, and levels of participation in class. David, a native of Thailand, earned a Bachelor's degree in audiovisual arts there. He hopes to go on for a master's degree in media or computer science here in the USA. In class, he often did not participate very much, doing his homework from other classes, not ready when called upon, etc. He had some registration and visa problems during the first half of the term, which may have contributed to his lack of classroom participation. Also contributing to his disinterest in the class was the fact that he had used the same coursebook at another ESL program 
the previous year. In fact, he actually dropped out for two weeks in the middle of the term. After he returned, however, his attitude and interest in the course were much better. He seemed motivated to work and go along with the instructor's guidelines. The researcher's perception of David's pattern of attitude was concurred by David's other teachers.

Hirai, from Japan, was a graduate of a high school in the midwestern USA, having studied there for two years. After high school he returned to Japan for a few months before coming to PSU. He hopes to attend PSU as an undergraduate. His participation in class was sporadic. He joined the class a week late, due to being moved up from a lower level. Usually, he was willing to answer questions and give his opinion. However, occasionally he would be very quiet in class. Nearly always, he came to class with his Walkman headphones on, and dropped them to his shoulders once class began. At times Hirai would stare blankly towards the floor six feet ahead of him during the class, so that the teacher sometimes wondered if he would have rather just put his headphones back on. He had increasing difficulty with the course, especially the last half. In fact, he was informed that he might not be promoted to the next level when there were only two weeks left in the term. After that point, he participated less in class. 
Jude was a quiet, organized student from Japan. She graduated from Otemae College in 1994 and had previously studied at PSU in a short ESL program with her college. She plans to study in the USA for two years, perhaps majoring in psychology. Although not outspoken, Jude was always ready to answer a question in class. She carries herself with an unassuming air of confidence, is always ready to answer a question, though not without pausing to think.

Kei was a Japanese student who had previously studied at the American Language Academy of the University of Portland. He plans to attend undergraduate business courses at PSU. An avid sportsman, Kei was sometimes persuaded to share his adventures skiing on Mt. Hood. He joined the class a few days after the start of the term and was a willing, but not eager, participant.

Momiko, from Thailand, had the highest educational background in the class (including the teacher). She graduated in '91 with a Bachelor' degree in Japanese, then earned a Master of Arts degree in advertising from Tokai University in Japan. Her future plans are to return to Thailand work with an advertising company. Although not talkative or eager for attention, Momiko was the most active participant in this class. She was usually ready with an answer, and her answers were often not only correct uses of the form, but also with a humorous touch. Because she is fluent in both Thai and Japanese, she was a well-liked 
social link between the six students in the class whose native language is one of those.

Shiroe, from Japan, graduated from St. Mary's College in Japan in ' 93 and, like Kei, attended the American Language. Academy before coming to PSU. She plans to attend the University of Portland as an undergraduate. Shiroe, a friend of Kei, has some other similarities with him. They are both active in sports, although shiroe prefers snowboarding to skiing, and she, like him, is was a willing participant in class. Shiroe joined the class two and a half weeks late, and increased her participation as the term progressed and she became more familiar with the others students and the teacher.

The final student, Yik Cheng, is from Taiwan. She immigrated to Canada in 1992, after graduating from college

in her homeland with a bachelor's degree in architecture. She

would like to continue her study of architecture at PSU. Yik Cheng was a quiet, shy student, but maintained a positive attitude and worked diligently. She was usually ready with an answer when called upon in class.

\section{LANGUAGE NOTEBOOKS}

Each subject described above created a language notebook (LN) to record out-of-classroom learning. They organized them individually, with some including almost 
exclusively vocabulary and idioms, while some contained other sections such as grammar points, book reports, and sports trivia. Because student investment in out-ofclassroom learning has been operationalized for this thesis in terms of written records in language notebooks, the quantity of student entries was tabulated for each student over time. The total number of words recorded was selected as an objective quantitative measure. The quantity of words for each student for each week that the notebooks were kept is listed in Table II.

These procedures were followed for this tabulation: counting was accomplished by two's (i.e: two words counted at a time), hyphenated words were counted as one word, numbers in the context of phrases were counted as one word while numbers at the head of entries in a list were not counted, abbreviations were counted as one word (e.g: "v" for "verb"), and native language writing was estimated depending on its length. The sum total of words recorded for the class is listed in Table III. 
TABLE II

LANGUAGE NOTEBOOKS

QUANTITY OF WORDS

\begin{tabular}{|c|c|c|c|}
\hline Date & $\begin{array}{l}\text { Number of } \\
\text { Students }\end{array}$ & Total Words & $\begin{array}{l}\text { Ave/ } \\
\text { Stud }\end{array}$ \\
\hline $9 / 27$ & 3 & 694 & 231 \\
\hline $10 / 3$ & 6 & 1196 & 199 \\
\hline $10 / 10$ & 6 & 1339 & 223 \\
\hline $10 / 17$ & 6 & 1355 & 225 \\
\hline $10 / 24$ & 6 & 1298 & 216 \\
\hline $10 / 31$ & 7 & 1348 & 193 \\
\hline $11 / 7$ & 7 & 1491 & 213 \\
\hline $11 / 14$ & 7 & 2297 & 328 \\
\hline $11 / 22$ & 7 & 2614 & 373 \\
\hline \multirow[t]{2}{*}{$11 / 28$} & 7 & 2114 & 302 \\
\hline & & 15,746 & 250 \\
\hline
\end{tabular}


TABIE III

LANGUAGE NOTEBOOKS

CLASS TOTAL WORDS RECORDED

Date David Hirai Jude Kei Momiko Shiroe Yik Cheng

$\begin{array}{lrrrrrrr}9 / 27 & & & 124 & & 301 & & 269 \\ 10 / 3 & 271 & 41 & 292 & 26 & 369 & & 197 \\ 10 / 10 & 168 & 169 & 459 & 119 & 186 & & 238 \\ 10 / 17 & & 134 & 500 & 37 & 369 & 173 & 142 \\ 10 / 24 & & 242 & 434 & 125 & 353 & 86 & 58 \\ 10 / 31 & 252 & 104 & 287 & 88 & 300 & 182 & 135 \\ 11 / 7 & 146 & 201 & 379 & 219 & 54 & 149 & 343 \\ 11 / 14 & 249 & 218 & 354 & 160 & 407 & 470 & 439 \\ 11 / 22 & 358 & 408 & 410 & 237 & 389 & 275 & 537 \\ 11 / 28 & 288 & 120 & 491 & 225 & 413 & 244 & 333\end{array}$

$\begin{array}{llllllll}\text { Tot: } & 1732 & 1637 & 3370 & 1236 & 3141 & 1579 & 2691\end{array}$

Ave/

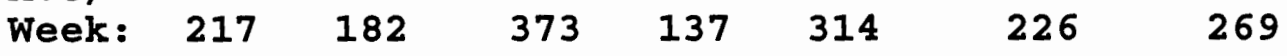


The bulk of student entries in their language notebooks were vocabulary words, definitions, and example sentences. As mentioned above, however, there were other types of entries, as well as differences between students in the format of the vocabulary and idiom listings. What follows is a sample of student entries, illustrating some of the variation.

"a la carte (adj + adv.) with a separate price for each item on the menu" -- David, 10/10.

"exclusive. ik-klu-siv. adj. 1.reserved for particular persons.

2. snobishly. aloof.:also.

(ex)

Hirai's club is the most exclusive club in N.Y." -- Hirai, 10/24

"resent [rezent] v.t. <(Japanese characters)> (More Japanese characters)

angry

ex) The students resented being treated as children. - Jude, 10/31

"Horse Race Breeders Cup ' 94

* Spring 3 years, over

$6 F$

* Juvenile fillies. 2 years $f$.

$11 / 16$ mile

* Distaff

3 years, over $f$.

$11 / 8 \mathrm{mile}$

Sprint

Juvenile

Distaff

Mile

Juvenile

Turf

Classic

1 million dollar

2 million dollar

3 million dollar"

- Kei, 11/7

"19. shut up

(I was told by my friend)"

to cause to stop talking

- Momiko, 10/31 
"had been researched

was shared

was wrestled

could not be contacted

might be touched"

-- Shiroe, 10/24, [This was in response to an assignment to find examples of passive voice in the newspaper.]

" $<1>$ The dancing Men

Role in the story:

Mr. Cubitt $\rightarrow>$ husband

Mrs. Cubitt $\rightarrow$ wife (Elsie)

Mr. Holmes $\rightarrow$ smart person in this story.

Slaney $\quad->$ Mrs. Cubitt;s friend in American.

Mr Cubitt was born in Norfolk, his family is very well

known in Norfolk. He met Elsie in London. Elsie is an

American, after they met a few weeks. She got married to Mr. Cubitt. ... < ? > Their love is so great. They can do anything for each other. But I thing if Mrs. Cubitt tell the trouble to Mr. Cubitt. It won't be happened. Now, they might be happy."

- Yik Cheng, 11/14

\section{INSTRUCTOR'S FEEDBACK ON LANGUAGE NOTEBOOKS}

Each week, the researcher responded to all students individually about their language notebooks. A grade of points out of ten possible was given, along with written feedback of varying length, but averaging about 50 words. often, the feedback would include comments or corrections about entries in the notebook for that week. The teacher/researcher never wrote in the language notebooks themselves, but on a separate piece of paper. When a student entry contained incorrect information, the teacher 
often gave a correction, but not in all cases. What follows are samples of feedback, chosen to illustrate the range of variety.

"Yik Cheng,

Sep 27

You have a good start here for your LN. I especially like that you have three sections (words, idioms, and sentences). Keep your eyes and ears open and you will find things to enter there, too.

Notes: a Viking is an ancient sea-faring robber from Scandinavia; peer mentors are people who are in a similar class and help each other.

Continue your good work.

$$
\text { - Jay } 10 \text { pts }
$$

The expression "take the bad with the good" means to be content to accept some bad points along with some good points. For example, if someone wants a new job, and it has long hours but high pay, the someone may be willing to accept the bad point (long hours) in order to get the good point (high pay)."

"Momiko,

Oct 10

Excellent work in your LN.

One word I noticed was 'burn out.' When used in your example sentence it should be 'The lamp in my bedroom was burned out,' but the verb in present tense is 'burn out.'

10 pts

- Jay

PS: I hate Jeopardy, too!"

"Kei,

Oct 12

I appreciate your effort to include grammar in your LN. Keep putting in what you learn outside the classroom.

Your goal was 2 or 3 words (or idioms, or new grammar tools) per day. See if you can meet that for next week. Or, we can adjust your goal if you would like to. 
One note: The Seattle company is spelled Boeing.

- Jay

8 pts"

"Shiroe,

24 Oct

Your verbs from the newspaper assignment are fine; but I would have liked to see more entries from other places. You have recorded nothing outside of the newspaper assignment.

Remember what is stated in the syllabus:

"Keep your LN with you all the time." It is intended to stimulate your learning on your own outside the classroom.

$$
\begin{aligned}
& \text { - Jay } \\
& 7 \text { pts" }
\end{aligned}
$$

"Jude, 31 Oct 94

Your LN is excellent, as usual.

$$
\begin{aligned}
& 10 \text { pts } \\
& \text { - Jay" }
\end{aligned}
$$

"Hirai,

14 Nov

You put example sentences for each word. Great! A few of the sentences seem a little odd to me (e.g:

"correspond"), so it might be a good idea to check them with your tutor before you hand in your LN.

I appreciate your effort, though.

8 pts

(More words would be better.)"

$$
\text { - Jay }
$$

TEACHER'S LOG

The teacher/researcher kept a log of observations and impressions during the term. This log also contains notes 
of conversations with other instructors. What follows is a listing of highlights of the log, chosen for their relevance to the research question and thesis in general. Any additions are set off with brackets [] .

9/21: Yesterday I felt discouraged that this class is so small ... I doubt my advisor will let me do my thesis with such a small group ... the stat results will be insignificant ... Lord, please open up a door to do my research this term. ...

They seemed to understand when I talked about out-ofclass learning and the LN. I started by explaining that there is a language learning problem -- expecting all the responsibility to be on the teacher. And that there are 2 sorts of students: sitters (like baby birds) and learners (who seek to learn, in and outside of class. David asked what I meant in the syllabus by "graded based on effort." "More words better grade?" he asked. "Yes" I said. They all signed up for conferences to discuss the LNs -- David signed up last, so he's up today!

9/23: During the conferences, Yik Cheng seemed the most interested in LNs, and had already noted some words in hers. Also, Momiko said she thinks it is important. I think that Jude feels the most uncomfortable about the out-ofclassroom learning idea, but she seems very "together" and will try. I forgot, with Momiko, to set any LN goal. I'm not sure if I should revisit it or not.

[later, after class] I asked Momiko after class if she wanted to set goal for her LN. She said she would think it over and let me know next week.

Also, let's talk about what I can observe in these students to see their motivation to learn outside class:

1) LN entries

2) Facial expressions about the topic of out-ofclassroom learning

3) Discussion in and out of class over out-of-class learning (share LNs with each other)

For them this week:

\section{LN Facial Expression Discussion (confst)}

David: just starting usually flat, even cynical smile I think.
He agreed with it, but not too enthusiastic. 


$\begin{array}{llll}\text { Yik } & \text { several } & \text { In class: flat. } & \text { Positive, especially } \\ \text { Cheng } & \begin{array}{l}\text { entries } \\ \text { already }\end{array} & \begin{array}{l}\text { Out of class } \\ \text { (conf): smiles }\end{array} & \begin{array}{l}\text { what she said about } \\ \text { keeping it }\end{array} \\ \text { "forever." } & \begin{array}{l}\text { when we } \\ \text { had conf }\end{array} & & \begin{array}{l}\text { Maybe it was said } \\ \text { in order to please. }\end{array} \\ \text { Momiko just } & \text { Flat. } & \text { Supported it, better } \\ & \text { starting } & \begin{array}{l}\text { Occassional } \\ \text { smile }\end{array} & \begin{array}{l}\text { than Japanese or } \\ \text { Thai way. }\end{array} \\ \text { Jude } & \text { Flat } & \text { Seems uncomfortable, } \\ \text { starting } & & \text { "I will try" }\end{array}$

9/28: [from chart like the above one] David: He often seems cynical, looking away and smiling, casual. After he read my note in his LN, he just looked away. No discussion about IN or out-of-class learning. Except, when he handed it in, he said "I didn't learn anything so far (over the weekend?) " ...

I should ask them how they feel about the out-of-class learning; and give them some assignment (for the field trip).

10/3: Biggest unexpected boost has been to pass around good examples of LNs and ideas. Hirai and David both asked for a good example LN for me to show them. Students in class are eager to read my written feedback. As soon as I hand it back they look and read it, no matter what I'm doing in class.

10/4: Michael Harvey suggested collecting LNs spontaneously, to encourage full-time work on it and carrying with them.

10/5: I'm picking up sometimes from Momiko that she is not happy. Maybe I'm reading between the lines, of her face and responses. Seems to be blank and without a smile often. Not all the time, though.

10/10: Just finished conference with shiroe. We had a much better time talking while walking than we did in office. She seemed to be much more quiet after the consent form.

10/20: About out-of-classroom learning, maybe the learning lab Grammar Mastery Program will be another avenue. 
The assignment I gave them last week (interviews) seems to go well; most of them learned new English (Yik Cheng said she didn't).

10/24: Class (most) misunderstood the assignment for newspaper, thinking they had to write in all 25 words, and that they therefore had to do no other words.

10/26: This group seems to be bored, rather than challenged. I ought to challenge them more.

Also, I need to talk more about LNs in class. Maybe on Monday. Some LN-sharing activity. I can't fill in this chart [signs of motivation for out-of-classroom learning] because I don't hear them talk about it. So far, my main motivation has been GRADING. (whew).

11/7: I met with 5 students in conference today

Some find LN great; some don't. Kei prefers specific assignments; Momiko and Yik cheng prefer it free-lance.

To motivate, I told Kei that he needs to put in more effort. I'll have to check out the taped interview conferences.

David seems unmotivated (in general) and depressed.

11/21: About their motivation for LNs, I must confess that I don't have any answers about that. It seems like a few good students try to learn outside of class, and they do a great job. A few others just do it half-way to make it through. I don't know if I helped any of them to learn outside the classroom.

Momiko already great student; already learning outside classroom.

*Maybe one question I can add to the survey: (Maybe hand out surveys for h.w.; do discussion day after)

1) How has the LN helped you?

2) What sugg do you have for future students who keep language notebooks?

3) How much do you intend to use it in future?

Jude: like Momiko. Maybe LN has helped her keep good record.

Yik Cheng: seems to really like the LNs, and intends to keep it up, I think. the grade.

Shiroe: seems to tolerate the LN, do it to perform for

David: For the grade. Always asking what specifically is needed for the grade.

Kei: For the grade. Already, doing his vocab cards. Although he did put in a lot of his own ideas. 
Hirai: Works hard enough, has improved. But not much signs of his getting into it.

Ask Michael: ever had any guys who really got into it?

\section{STUDENT/TEACHER CONFERENCES}

Twice in the term the teacher/researcher held conferences with each student individually. The first set was conducted on Sep 21, 22, 28, and oct 10. The latter two dates were for late arrivals Kei, Hirai, and Shiroe. In these initial conferences, the teacher generally learned about the student's background and discussed the course syllabus and language notebooks. Students were encouraged to ask questions, and most did.

During the language notebook part of the interviews, the teacher explained the concept of out-of-classroom learning. The taped conferences often show an exhortation during this part, such as "You can be a sitter or a learner. Which will you choose?" Also, the teacher described possible organization formats for language notebooks, and gave students colored tabs to use for that. Most students were asked to set a numerical goal for recording new language in their language notebooks, but they were generally hesitant to do so.

In some cases, the students not only understood the concept of out-of-classroom learning, but affirmed it. The interchange below took place on sep 22 with Momiko. It 
illustrates agreement between teacher and student on the value of out-of-classroom learning.

Teacher: I haven't always taught English, but I've taught other things, and it's always important to me that a person be learning all the time, not just in the classroom, and that what a person learns in the classroom is only a small piece and it doesn't mean anything if they don't go and use that.

Momiko: I think so too ... because when I studied in Japan, after you study in the classes, it's not enough because you stay one hour or one and a half hours; it's very short."

Some students, however, were uncomfortable with the assignment of out-of-class learning. The teacher asked Jude "Do you feel uncomfortable about this?" She replied "Actually, a little uncomfortable, but I will get used to it."

Also, students asked some questions about the notebooks, such as Kei, who asked if he could continue to use vocabulary cards rather than just the notebook. The teacher replied that he could, as long as he handed them in each week with his language notebook, and put other language in the notebook. A couple of students also asked if they could use native language in the definitions. The teacher gave them permission, assuring them that the notebook should be of use to them.

During the second round of conferences, on Nov $7 \& 8$, the students gave specific feedback to the teacher about their LNs. The teacher's purpose for these conferences were to update the students on their statuses in the class, as 
well as to ask for student feelings and suggestions about the class, including the LNs. Because the students had by this time used the LNs for several weeks, most of them had specific input when asked. Highlights of their interaction with the instructor about LNs during these conferences follow.

Yik Cheng: "Sometimes, if I write the word, and maybe next time I see the word, some word I can remember, maybe some word I can't. But if I read again I can easy to remember ... Sometimes, if I read some word ... maybe I read, like, outside reading, and I remember this is a word I have been read before and I find my notebook. If I didn't write [it] I can't [look it up] again. I like that."

Yik Cheng: "Vocabulary is more useful than sentences [in the LN]."

Momiko: [In response to "What are your impressions about the LN?"] "It help remind me of expressions and words ... But sometimes it's hard to remember all the new words and come back home and put it in the notebook."

Momiko: [In response to "Do you prefer more specific assignments for your LN, or more freestyle?"] "I like freestyle."

Hirai: "I don't really enjoy [the LN]." [Teacher: "Why?"] "Not really useful ... because it's easy to forget. I'm kinesthetic person, so write down again and again and again. ... Like just write down vocab, meaning, and then example, one sentence, is not enough... Like when I look at it and maybe next day it's gone."

Hirai: [In response to "What suggestions do you have for the next time I use these LNs?"] "That's your teacher's job."

Kei: [In response to "Would you prefer to have more structured assignments for your LN, or more freestyle?"] "I'd rather have LN assignments than do it on our own."

Shiroe: [In response to "What are your impressions about the LNs?"] "Very useful for me. I used to use before, when in room writing. Sometimes, people don't need LN, but in my 
case I really need a $L N$ and this is kind of for my myself. This system is very good for me."

[I suggested to siroe that she include better definitions and more example sentences.]

Jude: [In response to "Is keeping a LN hard?"] "It's hard, but I believe it's work well, so I will keep it."

Jude: [In response to "Do you refer back to your LN words?] "Not often refer back, but sometimes."

Jude: [In response to "Do you keep it with you?"] "I have small book, this size [she showed it to me, about 2" $x$ 4"], and I always carry it, keep track of assignments. Then, back home look up in dictionary. ... some words from reading assignments, some in class, when I hear a word that sounds familiar [but she does not know it], I write it down."

David: "When I write down, I ask [someone there] just one meaning [in context]. Then later have to look at many definitions in dictionary. ... Better to write the sentence it's heard in. ... Try inferring, then look it up later.

Good way to learn."

In addition to the student/teacher conferences, two discussions in class about the INs were audiotaped. The first was on Oct 6. The teacher asked the group "What works well for your LNs?" The recording quality was low, so much of the discussion is inaudible on the tape. However, each student shared one word that they had learned from using their LNs. In addition, Momiko mentioned that she uses hers like a diary. In general, however, the tone of the discussion does not seem to be enthusiastic.

The second recorded in-class discussion, held Nov 28, recorded better than the first. The atmosphere was informalized by the teacher bringing sodas for the class. then, he asked several questions about the class in general, 
then specifically about the INs, similar to the questions on the survey, which the students completed after this class. Highlights from their responses follow.

"Better [if LN was] no grade, extra credit if you do it." "Better to have a topic each week, not vocabulary. Feelings and culture, rather than just vocabulary." (another student agreed)

"Good to be a journal, graded."

"Give assignments from TV, then student tells story in class."

"Show [the students] it's fun to learn outside."

"Take them to movie and ask what learn from movie (teacher would pay)."

"Maybe LN is better for beginners ... new to words and culture. Advanced ones need to just remember. If I were to go to Japan, I would do this."

"Maybe too many words to remember [two/day]."

"Just writing it once is not enough to remember. Must use it many times."

[The following were in response to "How motivate students who weren't into it?"]

"A quiz over some words, from each person a little different."

"Give assignments. Arrange a language partner (one who fits). Arrange a group meeting with language partners."

"Show students it's fun to learn outside class. For example, a newspaper in class ..."

SURVEYS

The teacher administered surveys to all students at the end of the term (see appendix for survey form). The 
students completed the surveys after class, taking as much time as they wanted. The first side of the survey asked for scale scores by the student for various aspects of the class in two categories: "How much it helped" and "How much I liked it." The scoring was according to this scale: "0 = Little; 1 = Some; 2 = Much." The total scores for each question on the front side of the survey are listed in Table IV.

The reverse side of the survey requested narrative responses for several questions about outside-the-classroom learning. Those questions will be considered in turn. 
TABLE IV

SURVEY TOTAL SCORES

\section{HOW MUCH* HOW MUCH* \\ IT HELPED I LIKED IT}

1. Using a language notebook.

6

3

2. Conference with the teacher at the start of the term to review syllabus and plan language notebooks.

3. Conference with the teacher in the midale of the term to review status and discuss

language notebooks.

4. Homework assignments in the textbook.

9

5. Assignment to interview an American.

6. Assignment to look in a newspaper for passive phrases.

7. Teacher's comments on my language notebook.

*Total points from all students in each category; the maximum possible was 14 . 
"What was one interesting thing you learned OUTSIDE the classroom this term?" In general, the students answered that they had not learned much outside the classroom. For instance, Shiroe wrote "Actually, I don't have." However, one student, Yik Cheng, spoke highly of her tutor, "She told me lot of funs to me ... I really interested in her things." "What motivates you to learn outside the classroom?" The students mentioned interest and a desire to learn American culture. In addition, David wrote that "sometimes I feel bore to study much English."

"Has your language notebook helped you? If so, how?" The responses to this question varied from strongly negative to positive. One student said simply "No," while another wrote "I don't think so." Others felt it was only partially useful, such as Momiko, who answered, "Just a little. I put all new words I learnt in it. But it doesn't mean that I can remember all that words or use them correctly whenever I want to. I think $L_{N}$ is a small incomplete and incorrect dictionary. But it might help me in long term." A few students wrote that the IN was useful to them. One example is Shiroe, "When I watch TV such as movie, news and comedy, I alway with my language notebook, and then I try to pick up .. sometimes I catch words which I don't understand. If I didn't have a custom which I pick up some unclear word, I would forget those." 
"What would have made the language notebooks more interesting and valuable to you?" Not every student had suggestions for this question. However, two clear ideas came up. The first was from Momiko, "To put more things than only words and idioms. Maybe some interesting or neat culture, custom which are different from my country." The second was from Yik Cheng, "I think if I can choose a topic, I write everything that I want to write."

"What suggestions do you have for future students who keep Ianguage notebooks?" In response, Jude wrote, "if they just takes notes, it won't help at all. Maybe the teacher should give them a quiz to make them look over again." Also, Kei concurred with the idea of weekly topics mentioned by Yik Cheng under the previous question. Momiko's answer to this question was the longest of any student to any question. She wrote, "To keep it with them all the time. Put only new words you learn. Do not copy them from a dictionary just only want to have 14 words a week in your $L N$ to get 10 points. "Some weeks I put all new words I really learnt but you gave me 8 or 9 points but the week that I copied from dictionary you gave me 10 points so it might be better if you do not graded on $\mathrm{LN}$."

"Do you intend to keep record of your learning outside the classroom in the future?" Answers to this question varied, once again. Some students replied simply "No," or left the question blank. Others indicated they would keep a 
limited record, such as for new idioms only. In addition, a couple students wrote that they would keep a record. Yik Cheng responded, "Yes, because I always learn from life, It is practical."

The final question was open ended. Most students responded about non-LN aspects of the class. However, Kei wrote "This term, LN was like a vocabulary note. It was boring, so it should be more fun." In addition, on the bottom of the first side, a couple of students initiated extra input after the last item, "Teacher's comments on my language notebook." Jude wrote "but I want more [feedback on her LN]." Momiko's note was similar, "It will help if you correct some words or grammar and an example how to use that verb correctly. Not only "your LN is good as usual." 
CHAPTER V

DISCUSSION

At this point of the thesis documentation, it is crucial to look again at the original research questions:

What will empower ESL students to formalize and expand their out-of-classroom learning?

For ten weeks the teacher/researcher tried to empower his students to formalize and expand their out-of-classroom learning. What can be learned from that experience? In what ways did the results of this thesis answer these questions? The data recorded are varied, from teacher's log to taped discussions, from student surveys to tallies of words entered in language notebooks. The results of this research give insights into student motivation for out-ofclassroom learning; and the aim of this chapter is to discuss those insights.

\section{EVALUATING THE INTERVENTION}

There is great value in out-of-classroom learning, but most ESL students do not take full advantage of their rich learning environment. To consider what can be gleaned from the thesis results, each aspect of the teacher's 
intervention strategy to empower his students will be addressed in turn.

\section{Language Notebooks}

As the term went along, I began to pick up that most students were less enthusiastic than I was about their language notebooks. The following is from my teachers' log on 11/21:

"About their motivation for LNs, I must
confess that I don't have any answers about that.
It seems like a few good students try to learn
outside of class, and they do a great job. A few
others just do it half-way to make it through. I
don't know if I helped any of them to learn
outside the classroom."

I learned a lot about student feelings about the language notebooks through the second round of student/teacher conferences. Some had negative feelings, confirming my observations sumarized above. For example, Hirai said "I don't really enjoy [the language notebook] ... [It's] not really useful." On the other hand, some students felt the value of the language notebooks outweighed the cost in effort. Jude commented "It's hard, but I believe it's work well, so I will keep it." Also, Shiroe said "This system is very good for me."

At the end of the term, the student survey gave some valuable input about the desirability and usefulness of language notebooks (see Table IV). Out of a possible fourteen points, "Using a language notebook" received a 
score of only six for how much it helped, and a lowly three for how much they liked it. That is the lowest score for enjoyment of any of the seven items on the survey, and the point combination (nine) for the language notebooks is the lowest total. So, in the view of the class as a whole, language notebooks did not help much and were not terribly fun.

I concluded at the end of the term that language notebooks, as used in this class, were of only limited help. First, they were used mainly as vocabulary lists. This limited the impact for all-around learning outside the classroom. Furthermore, because the students generally wrote new words once only, and seldom -- if ever -- reviewed them, the students did not retain the words. Even worse than that, because the instructor did not make corrections on every entry listed, some of the student definitions were inaccurate. Therefore, as one student stated on the survey, "the language notebook is a small, incomplete, and incorrect dictionary."

In addition, the students were not inclined to keep the language notebooks with them all the time. They often just completed them in their rooms with a dictionary or book of idioms. While that type of exercise is a form of learning, it is a far cry from the intent of the teacher/researcher that students would be looking for chances to learn English all day long from the natural sources around them. 
Nevertheless, as I rethought the whole language notebook idea, I did learn several ways to improve it. First, they should be built to include a wide variety of information, rather than mainly vocabulary. One student suggested "To put more things than only words and idioms. Maybe some interesting or neat culture, custom which are different form my country." Furthermore, the information should be gathered from many sources. One student practiced the habit of noting the source of each entry she made. This gave her language notebook a diary aspect which was motivating to her.

The second way that language notebooks could be improved is by not grading them. Grading did indeed motivate some of the students. As noted in the teacher's $\log$ on 11/21, about half of the students seemed to do their language notebooks mainly for the grade. However, those students did not put in nearly as much effort as the others, and hated it. So, it is doubtful that there will be a positive long-term effect on their motivation for out-ofclassroom learning. However, those students that got most involved in their language notebooks may have done so even if they were not graded.

One student suggested during the Nov 28 class discussion, "Better [if LN was] no grade, extra credit if you do it." This student was one of those who seemed to be doing his LN mainly for the grade. For him, and others like 
him, some alternative to language notebooks should be provided. Removing the grade from the $\mathrm{LN}$ and making it one of several options for extra credit would accomplish that.

To address the problem of lack of retention of what is recorded in the language notebooks, a third improvement is to give personalized quizzes. This was suggested by a student in the survey, "A quiz over some words, from each person a little different." A teacher could collect the language notebooks from the class and generate a quiz for each person over material in that person's notebook. If language notebooks were optional, some alternative would have to be done for those not participating. Although this idea would definitely motivate students to review their notebooks, that value must be weighed against the cost of time required by the teacher.

The final suggested improvement to the language notebooks addresses the inconvenience of carrying a notebook around all the time. Although ESI students virtually swim in an environment rich in English, students do not enjoy carrying a book with them wherever they go to write it down. One student, Jude, had a solution to this problem. She carried a little black book with her, about 2 " $x$ 4", almost all the time. In it, she jotted down new words or idioms that she heard or read throughout the day, in addition to keeping track of appointments and assignments. Later, when she returned to her room, she would record the new language 
in her notebook along with the definitions from the dictionary or other sources. This seems to be a good model to follow.

\section{Student Goal-Setting}

The second aspect of the teacher/researcher's strategy to empower students to learn outside the classroom was goalsetting with individual students. At the beginning of the term, during student/teacher conferences, most students were asked to set personal goals for entries in their language notebooks. Judging from the conference tapes, this attempt at goal-setting did not work well, despite the endorsement of goal-setting by Frymier (1974) and Grossnickle (1989). In fact, most students seemed to feel uncomfortable with the whole idea. It seemed as though the students not only saw academic goals as the teacher's responsibility, but also they were hesitant to assign themselves work to do.

Furthermore, only one student out of the seven kept a personal numerical goal set at the start. Other students, if numerical goals were set, seemed to forget about them. One student, who never set a goal at all, had the second highest number of words recorded. During the term, the teacher suggested to several students, who were not recording much their language notebooks, to simply aim for two new vocabulary words per day, which some of them did. However, the goal-setting by the students themselves did not 
motivate these students, even though the teacher/researcher had high hopes for this technique.

As I reflected upon the failure of student goal setting, I considered alternate explanations. One potential explanation for this is that student goal-setting may be highly culture-dependent. People of Japanese, Thai, or Taiwanese culture have their own ways of ordering their lives and priorities. In this case, the teacher challenged new students one by one to set a goal, right in the midst of a one-on-one conference. While that may work with some American students, it did not with this group.

\section{Communication of Homework and Language Notebook Intent}

As discussed in the literature review, Renchler's Theory of Personal Investment (1991) focuses attention on meaning as a determiner of motivation. Therefore, I tried throughout the term to communicate the meaning of out-ofclassroom learning for my students. They were already motivated to learn English, motivated enough to expend the time and finances for PSU courses, so I tried to communicate, both in class and individually, how out-ofclassroom learning is linked with English language gain as a whole.

The effectiveness of this aspect of the strategy was difficult to assess. While students responded in varying ways to specific homework assignments and to the language notebooks, the on-going communication of homework 
assignments and the purpose of the notebooks was a background for the whole class. Nevertheless, some insights can be suggested about specific homework assignments and the student/teacher conferences.

These students knew how to do homework. While the broad concept of out-of-classroom learning may have been a new one, completing homework assigned by the teacher was a familiar practice. According to the survey (see Table IV), the students valued textbook assignments as much as anything in the class, and even liked doing them. However, there were two specific assignments to be recorded in the language notebook, which were not so highly rated. One was to interview an American to learn tips for either applying for a job or for being a successful student; the other was to scan a newspaper for passive voice. In both cases, little was recorded in the students' language notebooks. Nevertheless, all students actively worked on every specific out-of-class assignment, so homework was motivating.

The most effective environment for communicating the intent of the language notebooks was in a student/teacher conference. In the initial conferences, some -- but not all - students seemed to grasp the concept and expressed identification with it and/or uncomfortable feelings about it. By the time of the mid-term conferences (Nov $7 \& 8$ ), the students had enough experience with the language notebooks to have strong opinions about them. Therefore, 
the teacher asked questions to learn their impressions and suggestions.

In addition to the valuable input made at this point, such as the difficulty of retaining new vocabulary from the notebooks, the conferences may have been a motivation in themselves. The tally of the quantity of student entries in the language notebooks (Tables II \& III) shows a dramatic jump on Nov 14 which was sustained for the rest of the term. Nov 14 was the first collection of the notebooks after the second round of student/teacher conferences.

I did not recognize this general jump in student performance until after the term was over. In analyzing it then, I considered other potential explanations for it. For example, their studying demands in other classes may have decreased at that point. However, it seems unlikely that the last three weeks of a term would be less demanding than the other weeks. Another potential explanation might be that the weaker students, which had by that point been pointed by the teacher to a standard of two new vocabulary words per day, picked up the slack in the class average. While the latter factor contributed to the increase in language notebook use at the Nov 14 point, the student conferences seem to be the most important influence. This is supported by the survey, in which the students gave the mid-term conference the highest rating for both usefulness and enjoyment (tied with textbook assignments, see Table 
IV). The most motivating aspect of the second round of student conferences was probably the elicitation of feelings and suggestions from individual students.

\section{Weekly Feedback}

The weekly feedback to students on their language notebooks was motivating. As the term progressed, it was easy to see the student interest in my written feedback. This teacher's log entry is from 10/3: "Students in class are eager to read my written feedback. As soon as I hand it back they look and read it, no matter what I'm doing in class."

Once again, the student survey at the end of the term provided valuable insights. The students rated weekly feedback on language notebooks highly on the first page of the survey (Table IV), but it was their written comments which carried more weight. Although there was no narrative question on the survey regarding this feedback, two students -- the ones with the most effort put in on their language notebooks, incidentally -- took initiative to write unsolicited notes encouraging more feedback. Especially requested were specific corrections and examples. One of these students, who was not at all outspoken, wrote a direct request for teacher feedback in the blank space under the score on the first page of the survey, "I want more." 
General

The students generated a couple of other insights, in addition to the above discussion. One suggestion which surfaced in the class discussion on Nov 28, and also in the survey, was to have a topic assigned each week. Each student would focus their out-of-classroom learning on that topic for that week. Also, students may also freewrite on that topic. This idea seems to strike a balance between teacher-direction and student-initiative.

Another suggestion from the students to increase outof-classroom learning was the assignment of language partners. This also came up on Nov 28. If a teacher arranged a group meeting between students and language partners, that may spawn relationships which would lead to rich learning. This idea is especially valuable in light of the social nature of language learning.

One interesting trend in this class that I noticed only after the term was over is a Iink between student sex and language notebook performance. As shown in Table II, the four females in the class achieved the top four places in terms of average number of words entered per week. In fact, the average of the males as a group (179) was only $61 \%$ of the females' average (295). Although the sample size is small, these results suggest that, for this group of students, females may have been more adaptable to language notebooks, and that males may have benefited from 
alternative methods of empowerment for out-of-classroom learning. I posed the question to myself in my teacher's $\log$ on 11/21, wondering if Michael Harvey's experience with his students has been the same.

Part of my rethinking and evaluation was discussions with other teachers. I spoke with Michael Harvey many times during the process of this research. One of his suggestions was to collect the language notebooks at unannounced times, so that the students would be motivated to keep them with them all the time. Also, regarding differences between sexes, his experience with grammar notebooks is consistent with my findings in this sample: women as a group have done better than men.

In addition, I discussed out-of-classroom learning with more than 40 colleagues at a recent Oregon Teachers of English to Speakers of Other Languages (ORTESOL) conference. I presented a workshop on the topic of empowering students for out-of-classroom learning. In the workshop, participants brainstormed and then shared on these topics: sources of out-of-classroom learning, hinderances to it, and techniques to empower students for it.

This experience was very valuable to me. For one thing, the high attendance and active participation in this optional workshop confirmed to me that this is a worthwhile area to research and practice. For another thing, I learned a lot from the input of my colleagues. A key insight to me 
was the agreement among most of the group that fear was a dominant hinderance to ESI students' out-of-classroom learning. That needs to be addressed in follow-up research. Another insight that I will use in the future is this simple technique: assign students to go out into the environment and bring back to class nuggets of language that interest them, such as bumper stickers, signs, menus, and brochures, and share these nuggets with the class. This techniques focuses on the language itself, and is versatile.

\section{CONCLUSION AND REVISED GENERAL PLAN}

\section{Reflection}

The discussion above ties the Results (Chapter IV) with the research questions. I would like to conclude by reflecting on the broader spectrum, discussing the following questions as I look back over the thesis. First, how do my findings fit with the literature? second, what stands out as I reflect on the research process? Finally, how will this thesis affect my future teaching?

I used primarily the action research process outlined by Nunan (1992), and it worked well. The research questions were always before me, and without a doubt I learned a lot about motivating students for out-of-classroom learning. However, the emphasis Nunan gives to actual change in my classroom set the stage for disappointment when my students did not respond as I had hoped. Perhaps I was too hard on 
myself in the $11 / 21$ journal entry, and perhaps Nunan's emphasis is not so much on immediate change, but over the long run with future students.

One tip from the literature that miserably failed was student goal-setting (Frymier, 1974 and Grossnickle, 1989). I want to keep in mind in future reading that any given article is written based on experience in a limited setting and is intended for a certain audience to benefit from. Critical reading, combined with cultural sensitivity will help. Perhaps even student goal-setting, itself, can work with students of various cultural backgrounds, if it is adapted to suit them.

As I reflect over the thesis process, the outstanding things are the student relationships and the surprising discoveries. The subjects for this thesis, my students, worked hard in a new and often uncomfortable project. I appreciate them very much and will remember them longer than anything written on these pages. In addition, as the thesis unfolded, a revised general plan, as outlined below, emerged.

Finally, how will this thesis affect my teaching? First, I plan to become a teacher/researcher in the regular practice of my profession. As I told my students to be "learners," rather than "sitters," so ought I to be. Second, I want to be aware of the differences in individuals in my classrooms: differences between cultures, between 
sexes, between learning styles, between personalities. Time and energy to act on this awareness may be limited; however, even if a class is large, I would like to teach students in the way they learn best. Thirdly, I hope to follow-up the lessons learned about motivating students to learn outside the classroom, implementing the following revised general plan.

\section{Revised General Plan}

Having completed one full cycle of the action research process, a revised general plan leads into the follow-up cycle (see Figure I). This plan calls for a modified intervention to address the same classroom issue, how to empower students to formalize and expand their out-ofclassroom learning. The new intervention follows.

1. Discuss and interact with students over the issue of out-of-classroom learning from the beginning, and all the way through the research cycle. Ask the students for their ideas about how to address this issue, and later get their evaluation about the results. Their input validates the research. Have at least two individual student/teacher conferences during the term, with at least 20 minutes in each devoted to discussion about out-of-classroom learning. Show empathy for students' fears about talking with Americans, and share cultural tips when appropriate. Adjust the intervention as seems best in light of student input. 
2. Assign students to keep a written record of their out-of-classroom learning. One option for this record is a language notebook; other options are welcomed. Extra credit may be earned by effort in this assignment, but it will not be graded. Encourage a wide variety of input and sources for the out-ov-classroom learning, including culture. Also, suggest that students keep a mini-notebook ("little black book") throughout the day, from which to transfer information to an organized notebook.

3. Collect the students' records of out-of-classroom learning weekly and give thorough feedback on the specific information that was entered that week.

4. Encourage language partners.

5. On a weekly basis, assign students to bring in a nugget of English language from the environment around them. Have them each share them with the class, and encourage interaction among the group. Sample assignments: a bumpersticker, a menu, a magazine article, a sign, anything that interests you, etc...

This effects of the above intervention should be monitored in the following ways:

a. Examine the content and form of students' records of out-of-classroom learning. Check for variety, quantity, format, changes throughout the term.

b. Take good notes, or tape record, class discussions and student/teacher conferences. 
c. Keep a teacher's log.

d. Give students a survey at the end of the term, asking their opinions and suggestions about out-of-classroom learning and specific assignments in the class.

In conclusion, I feel that action research was effective and appropriate for investigating the research question. "What will empower ESL students to formalize and expand their out-of-classroom learning?" is a question that cannot be answered with a cut and dried formula. It has many faucets and is dynamic. The way to empower them will be unique for each class of students, and so must be discovered by teachers individually as they make contact with their students. That is what action research is for. 
REFERENCES

Amundson, Kristen J. (1991). 101 Ways Parents Can Help Students Achieve. Arlington, VA: American Association of School Administrators.

Brewster, E. Thomas and Elizabeth S. Brewster (1981). Language Learning and Mission. Pasadena, CA: Fuller School of World Mission.

Carroll, Michael (1994). "Journal Writing as a Learning and Research Tool in the Adult Classroom" TESOL JOURNAL, Autumn 1994, 19-22.

Carr, Wilfred and Stephen Kemmis (1986). Becoming Critical: Education, Knowledge and Action Research. Philadelphia: Falmer Press.

Celce-Murcia, Marianne and Sharon Hilles (1988). Techniques and Resources in Teaching Grammar. New York: Oxford.

Cooper, Harris (1989). Homework. White Plains, NY: Longman .

Doyle, Mary Anne E. and Betsy S Barber (1990). Homework as a Learning Experience. Washington, DC: National Education Association. 
Eisenhart, Margaret and Hilda Borko (1993). Designing Classroom Research: Themes, Issues, and struggles. Boston: Allyn and Bacon.

Elliot, John (1987). "What is action-research in schools?" Journal of Curriculum Studies vol 10, no 4, 1978. England, David A. and Joannis K. Flatley (1985). Homework, and Why. Bloomington, IN: Phi Delta Kappa Educational Foundation.

Frymier, Jack R. (1974). Motivation and Learning in School. Bloomington, IN: Phi Delta Kappa Educational Foundation.

Frymier, Jack R. (1985). Motivation to Learn. Bloomington, IN: Phi Delta Kappa Educational Foundation. Gerngross, Gunter and Herbert Puchta (1992). Creative Grammar Practice: Getting Learners to Use Both Sides of the Brain. Harlow, England: Longman.

Gigous, Goldie Marie (1974). Improving Listening Skills. Dansville, NY: The Instructor Publications, Inc. Gonder, Peggy Odell (1991). Caught in the Middle: How to Unleash the Potential of Average Students. Arlington, VA: American Association of School Administrators. Goswami, Dixie and Peter R. Stillman (1987). Reclaiming the Classroom: Teacher Research as an Agency for Change. Portsmouth, NH: Boynton/Cook.

Grossnickle, Don R. and William B. Thiel (1988). Promoting Effective Student Motivation in School and 
Classroom: A Practitioner's Perspective. Reston, VA:

National Association of Secondary School Principals.

Grossnickle, Don R. (1989). Helping Students Develop

Self-Motivation: A Sourcebook for Parents and Educators.

Reston, VA: National Association of Secondary School

Principals.

Hubbard, Ruth Shagoury and Brenda Miller Power (1993).

"Finding and Framing a Research Question" in Patterson, L.,

Santa, C., Short, K., and Smith, K., ed. Teachers Are

Researchers: Reflection and Action. Newark: International

Reading Association. pp 19-25.

Johannesson, Ingvar (1967). Effects of Praise and

Blame. Stockholm: Almquist \& Wiksell.

Kemmis, Stephen (1988). "Action Research in Retrospect and Prospect" in The Action Research Reader, 3 rd ed, Victoria: Deakin University Press.

Kemmis, Stephen, and Rogin McTaggart, eds. (1988). The Action Research Reader, 3rd ed, Victoria: Deakin University Press.

Krashen, Stephen (1981). Second Language Acquisition and Second Language Learning, Oxford: Pergamon.

Laconte, Ronald T. and Mary Anne Doyle (1986).

Homework as a Learning Experience. Washington, DC:

National Education Association. 
Lloyd, Bruce A. and Rosa C. Lloyd (1986).

"Teaching/Learning: The student Viewpoint." eading Horizons, XXVI, 4, 266-269.

McFarland, Katherine P. and John C. Stansell (1993). "Historical Perspectives" in Patterson, L., Santa, C., Short, K., and Smith, K., ed. Teachers Are Researchers: Reflection and Action. Newark: International Education Association. pp 12-18.

Mohr, Marian M. and Marion S. MacLean (1987). Working Together: A Guide for Teacher-Researchers. Urbana, IL: National Council of Teachers of English.

Nixon, Jon (1981). A Teacher's Guide to Action Research. London: Grant McIntyre Ltd.

Nunan, David (1992). Research Methods in Language Learning. New York: Cambridge University Press.

Oja, Sharon Nodie and Lisa Smulyan (1989).

Collaborative Action Research: A Developmental Approach. New York: The Falmer Press.

Olympia, Daniel (1992). "Homework Completion and Accuracy: Managed Interventions." PhD dissertation, University of Utah. (Order \#DA9227938).

Papandreou, Andreas (1991). "Homework in Teaching and Learning". Paper presented at the Annual Meeting of the International Association of Teachers of English as a Foreign Language (Nicosea, Cyprus, 1991). 
Raffini, James P. (1988). Student Apathy: The Protection of Self-Worth. Arlington, VA: American Association of School Administrators.

Renchler, Ron (1991). Student Morivation, School Culture, and Academic Achievement: What School Leaders Can Do. Eugene, OR: Oregon School study Council. Shockley, Robert J. (1964). Using Homework as a Teaching Tool. Teachers Practical Press, Inc. Strang, Ruth (1968). Guided Study and Homework. Washington DC: National Education Association. Van Lier, Leo (1988). The Classroom and the Language Learner, New York: Longman.

Wlodkowski, Raymond J. (1978). Motivating and Teaching: A Practical Guide. Washington DC: National Education Association. 
APPENDIX 
SURVEY

This survey is for Jay Neuharth's thesis research. Thank you for your help.

Name

Date

Please answer the following questions in both columns according to this scale: $0=$ Little; $1=$ Some; 2 = Much. The left column is for how much you feel that part of this course helped you, and the right column is for how much you liked it.

HOW MUCH

HOW MUCH

IT HELPED

I LIKED IT

Ex :

1

Meeting FIVE times a week.

$\underline{0}$

1.

Using a language notebook.

2.

Conference with the teacher

at the start of the term

to review syllabus and

plan language notebooks.

3.

Conference with the teacher

in the middle of the term

to review syllabus and plan

language notebooks.

4.

Homework assignments in

the textbook.

5.

Assignment to interview

an American.

6.

Assignment to look in a

newspaper for passive phrases.

7.

Teacher's comments on my

language notebook. 


\section{SURVEY (Page 2)}

What was one interesting thing you learned OUTSIDE the classroom this term?

What motivates you to learn outside the classroom?

Has your language notebook helped you? If so, how?

What would have made the language notebooks more interesting and valuable to you?

What suggestions do you have for future students who keep language notebooks?

Do you intend to keep record of your learning outside the classroom in the future? If so, how?

Please feel free to make any other comments about the LN's or other aspects of this class. I enjoy your input. 